\title{
Aviation Medicine
}

\section{Medical emergencies in the air}

\author{
I: Incidence and legal aspects
}

\author{
F JOHN MILLS， RICHARD M HARDING
}

\begin{abstract}
"But a Samaritan, as he journeyed, came to where he was; and when he saw him, he had compassion."1

Air France has estimated that for three out of every four life threatening medical emergencies occurring during flight a doctor is a passenger on board the aircraft. ${ }^{2}$ According to Air Canada the incidence may be as high as $90 \%{ }^{3}$ whereas internal surveys by other airlines mention lower figures of between $40 \%$ and $50 \%$. Some of the doctors who have responded to requests for medical assistance during flight have been critical of the emergency medical facilities provided; others have been disturbed by the lack of diagnostic and therapeutic equipment aboard aircraft, ${ }^{4-8}$ the apparent failure of airlines to screen passengers for their fitness to fly, ${ }^{5}$ and the lack of gratitude expressed by the airline to the doctor who has responded unselfishly to the emergency ${ }^{8}$ In an American study ${ }^{9}$ of 42 doctors who had responded to a total of 62 incidents, only one considered the medical equipment on board the aircraft to be adequate and just five received written thanks from the airline. At present, in the United States, the Public Citizen Health Research Group, the Aviation Consumer Action Project, and 25 doctors are suing the Federal Aviation Administration to force it to require commercial airlines to carry additional medical equipment and drugs on all flights. ${ }^{3}$
\end{abstract}

\section{Incidence of medical emergencies}

Some doctors appear to have an "ancient mariner" effect" while travelling by air so that they find themselves attending numerous inflight emergencies; others-probably the majority - have never been troubled. The few statistics on such instances come from reviews of flight attendant reports, analyses of the number of unscheduled landings made for medical reasons or the number of inflight deaths, and information actively solicited from doctors who have been concerned in such incidents. These figures have to be interpreted with care since many factors, such as the nature of the airline's operation and its willingness or otherwise to accept seriously ill patients for humanitarian reasons, may bias the results. For example, a domestic airline may have a lower incidence of inflight deaths than an international airline simply because an aircraft can be

RAF Institute of Aviation Medicine, Farnborough, Hants F JOHN MILLS, MA, MB, squadron leader RICHARD M HARDING, MB, DAVMED, squadron leader

Correspondence to: Squadron Leader F John Mills, Janssen Pharmaceuticals Ltd, Marlow, Bucks. diverted to another airport more rapidly on an overland domestic flight than on an intercontinental transoceanic route.

Recently all inflight accident and medical incident reports submitted by British Airways cabin staff during 1979-80, when over 17 million passengers were carried, were reviewed. ${ }^{10}$ of the 1063 accidents reported, only eight were considered to be "major" (three were cases of fracture, two of concussion, one of laceration requiring sutures, one of dislocation, and one of loss of consciousness); there were eight deaths during flight. Since half the accidents occurred to flight attendants, the chance of a passenger having a "major" accident was remarkably small (one in 4.25 million). Interestingly, the overall ratio of flight attendant to passenger accidents was $3 \cdot 7: 1$, which reflects both the greater mobility of the first group within the aircraft and the importance of including the crew in all surveys. By contrast, only four out of a total of 1328 medical incidents concerned the crew, so that the "attack rate" for passengers was about one in 13000 -the same figure as that quoted by Qantas ${ }^{11}$ for passengers needing inflight care by doctors or nurses during 1977, though the corresponding figure for 1976 was one in 21000 . In passengers whose disability had been notified to British Airways before the flight the rate was one in 350-a similar finding to that of the Air France Medical Department. ${ }^{12}$ The ratio of total incidents on intercontinental flights to those on European and domestic flights recorded by British Airways was nearly $4: 1$, but the incident rate for each cannot be calculated from the quoted figures, ${ }^{10}$ and they cannot be compared with figures from other airlines because of differences in reporting procedures. There is a need to standardise crew reports to ensure that meaningful statistics are obtained. Nevertheless, a long flight may be expected to produce more medical problems because of the greater exposure to factors ranging from immobility and hypoxia to the effects of duty free alcohol. A reasonable prediction is that medical help will be sought (but not necessarily required) on one in 50 international flights on wide bodied aircraft. ${ }^{11}$

\section{CAUSES}

The most common medical problems encountered by British Airways were associated with the central nervous system, closely followed by those due to stress and anxiety $(16 \%$ of total) and those affecting the cardiovascular system (15\%), the alimentary system $(12 \%)$, and the respiratory system $(10 \%) .10$ In an earlier study by the British Overseas Airways Corporation ${ }^{13}$ of 377 medical incidents, 15 were due to angina, 24 to heart failure, one to cardiac arrest, 22 to dyspnoea, five to asthma, and one to pulmonary embolism. The commonest incidents were neurological with 55 episodes of fainting, six of fits, and 33 of mental illness. 
These studies, and others, were based on retrospective medical judgments, and information regarding the severity of medical problems was not provided. Thus the latter can only be gauged indirectly from the need to make unscheduled landings. This decision will be affected by the level of training of the cabin crew, in the absence of a doctor on board, and by the sophistication of the medical equipment carried. For example, between 1975 and 1979 Qantas made 16 unscheduled landings, of which 10 were for chest pain or suspected myocardial infarction. ${ }^{11}$ Between 1964 and 1968 American Airlines ${ }^{14}$ made an average of one unscheduled landing for every one million passengers carried, which is high when compared with one in 8.5 million for British Airways in 1979-80, ${ }^{10}$ undoubtedly because at that time American Airlines was flying only domestic routes. Rarely was a doctor on board at the time of these landings, so the diagnoses were based mainly on crew reports which sometimes lacked information. Though half of the landings were probably unnecessary, these instances have not been excluded from the analysis: heart attack (real or suspected) and chest pain accounted for 33 of the 105 reports, syncope for 21 , and dyspnoea for 20 .

Cardiovascular disease is probably the most common cause of serious illness during flight, as shown by studies on deaths which have occurred from natural causes on board aircraft. Of 90 deaths reported in BOAC passengers from 1947 to $1967,{ }^{13}$ 34 were due to myocardial infarction, six to heart failure, seven to cerebrovascular accidents, 13 to cancer, three to leukaemia, three to renal failure, two to pulmonary embolism, and two to cirrhosis of the liver. This distribution of diagnoses is very similar to a series of 25 deaths reported by Qantas between 1975 and 1979."11 Nine could not have been prevented wherever they had occurred and a further two were likely to have been fatal if they had occurred anywhere outside a hospital environment.

\section{Legal aspects of emergency care}

The provision of medical care by airlines during flight covers the selection of first aid kits, the training of flight attendants, and the allocation of adequate space for treatment. Of paramount importance are certain legal considerations which apply to the airline and to itinerant doctors.

All doctors should feel that they have a moral duty to help anyone in distress but recently there has been a trend for doctors not to declare themselves at accidents or similar emergencies for fear of subsequent litigation. Under the law practised in most British Commonwealth countries and the United States there is no legal obligation to give aid to a stranger, but in most European countries it is a criminal offence not to render assistance. The legal onus to help will therefore depend on geography and possibly the nationality of the carrier. Similarly, geography may be relevant should litigation ensue, because of medical insurance cover: for example, a British doctor on holiday in the United States will not be covered by his defence society for litigation arising in that country. The "wealth" of the airlines should perhaps be used to underwrite any damages ${ }^{6}$ but the recent demise of Laker and Braniff and the reported financial problems of some of the major international carriers hardly support the notion that the airlines are wealthy.

Of the 42 doctors in the American study who had responded to inflight incidents, ${ }^{9}$ at least half were reluctant to answer requests for medical assistance, mainly because they were afraid that the problem would be outside their usual field of practice. This is understandable since inexperience may be no defence against allegations of negligence. For this reason airlines have to be cautious in their choice of equipment for first aid kits, lest it be beyond the expertise of the user. For example, endotracheal tubes should possibly be provided for use by doctors, ${ }^{4}$ but many doctors have not passed a tube for many years because of their specialisation. Under cramped, possibly turbulent, conditions it might be overoptimistic to expect a successful intubation. Those who condemn this argument and can intubate with ease may still be subject to litigation because of their lack of experience in aviation medicine. For instance, a rapid decompression to $35000 \mathrm{ft}(10668 \mathrm{~m})$ can produce endotracheal cuff pressures which greatly exceed those known to cause tracheal damage. Would the doctor be aware of the need to correct the cuff pressure? Even when properly set for cruise altitude the cuff pressure can still fall below that required to prevent aspiration when the aircraft returns to ground level. ${ }^{15}$

Legal considerations also determine the choice of drugs for first aid kits. British operators might wish to make diamorphine available in an emergency kit for use by doctors, but if their aircraft are to land in the United States they could be impounded because they are carrying a drug which is prohibited even from controlled medical use in that country. British Airways' A50 first aid kit contains four medicines available only by prescription and one controlled drug, which may under certain well defined conditions be administered by a member of the cabin crew. Potential legal problems have been overcome by close cooperation with the Department of Health and Social Security and other authorities based on the firmest assurances that the use of these drugs will be correctly and dutifully recorded by crew attendants who have been trained in their use. Legal authority to prescribe and dispense has been given by the DHSS and the Home Office and is contained in instructions listed in the British Airways cabin crew manual.

Finally, to overcome these problems it has been suggested that doctors should take their medical bags along with them when travelling by air, being exempt from any excess baggage charges that may result. ' This idea has received support from the American Medical Association who have even outlined a suitable list of medicines to be carried. ${ }^{16}$ At present, however, it is impractical on all but domestic flights since most countries prohibit the import and export of medicines unless they are required for the person's own health or the import/export has been previously approved. Since these regulations often include medicines other than controlled drugs, doctors should be fully aware of their legal vulnerability in this area.

Next week's article covers the use of first aid kits, emergency treatment during flight, and recommendations for preventing medical emergencies.

\section{References}

1 St Luke, chap X, verse 33. The Holy Bible (revised standard version).

${ }^{2}$ Pasquet J. Emergency medical kits aboard aircraft. Aviat Space Environ Med 1977;48:882-5.

${ }^{3}$ Anonymous. Suit seeks airline carriage of emergency medical gear. Aviation Week and Space Technology 1982;117:41.

${ }^{4}$ Rennie ID. Medical hazards of air travel. Br Med f 1977;ii:515.

5 Callanan JG. Medical hazards of air travel. Br Med $\mathcal{f} 1977$;i:1473-4.

${ }^{6}$ McLaren HC. Medical hazards of air travel. Br Med f 1977; ii :44.

${ }^{7}$ Jolly R. Medical hazards of air travel. Br Med f 1977; ;i :637-8.

${ }^{8}$ Lawrie J. Medical responsibilities of airlines. Br Med f 1981;282:320.

${ }^{9}$ Hays MB. Physicians and airline medical emergencies. Aviat Space Environ Med 1977;48:468-70.

${ }^{10}$ MacLaren RB. In-flight medical care by flight attendants-an assessment of overall needs. Preprints of the 1982 meeting of the Aerospace Medical Association. Washington, DC: Aerospace Medical Association, 1982: 305-6.

1 Davies GRW, Degotardi PR. Inflight medical facilities. Aviat Space Environ Med 1982;53:694-700.

${ }^{12}$ Lavernhe J, Lafontaine E, Lequesne M. Transportation of patients in commercial aircraft. Aerospace Med 1967;38:525-7.

${ }^{13}$ Anonymous. Illness in the clouds [Editorial]. Br Med f 1975 ;i:295.

${ }^{14}$ Schocken V, Lederer LG. Unscheduled landings for medical reasons: a five year survey of the experience at American Airlines. In: Busby DE, ed. Recent advances in aerospace medicine. Dordrecht, Holland: Reidel Publishing Co, 1970:126-9.

${ }^{15}$ Stoner DL, Cooke JP. Intratracheal cuffs and aeromedical evacuation. Anesthesiology 1974; $\mathbf{4 1}: 302-6$.

${ }^{16}$ American Medical Association commission on emergency medical services. Medical aspects of transportation aboard commercial aircraft. $\mathcal{F} A M A$ $1982 ; 247: 1007-11$. 